\title{
Missouri Mothers and Their Children: A Family Study of the Effects of Genetics and the Prenatal Environment
}

\author{
Valerie S. Knopik, ${ }^{1,2}$ Andrew C. Heath, ${ }^{3}$ Kristine Marceau, ${ }^{4,1}$ Rohan H. C. Palmer, ${ }^{1}$ John E. McGeary, ${ }^{5,1}$ \\ Alexandre Todorov, ${ }^{6}$ and Allison Schettini Evans ${ }^{7,2}$ \\ ${ }^{1}$ Division of Behavioral Genetics, Rhode Island Hospital; Department of Psychiatry and Human Behavior, Brown University, \\ Providence, Rhode Island, USA \\ ${ }^{2}$ Warren Alpert School of Medicine, Brown University, Providence, Rhode Island, USA \\ ${ }^{3}$ Midwest Alcoholism Research Center, Department of Psychiatry, Washington University School of Medicine, St Louis, \\ Missouri, USA \\ ${ }^{4}$ Center for Alcohol and Addiction Studies, Brown University, Providence, Rhode Island, USA \\ ${ }^{5}$ Providence Veterans Affairs Medical Center, Providence, Rhode Island, USA \\ ${ }^{6}$ Department of Psychiatry, Washington University School of Medicine, St Louis, Missouri, USA \\ ${ }^{7}$ Memorial Hospital, Pawtucket, Rhode Island, USA
}

\begin{abstract}
The Missouri Mothers and Their Children Study (MO-MATCH) was specifically designed to critically investigate prenatal environmental influences on child attention problems and associated learning and cognitive deficits. The project began as a pilot study in 2004 and was formally launched in 2008. Participants in the study were initially identified via the Department of Vital Statistics birth record (BR) database. Interview and lab-based data were obtained from: (1) mothers of Missouri-born children (born 1998-2005), who smoked during one pregnancy but not during another pregnancy; (2) biological fathers when available; and (3) the children (i.e., full sibling pairs discordant for exposure to maternal smoking during pregnancy (SDP). This within-mother, between-pregnancy contrast provides the best possible methodological control for many stable maternal and familial confounding factors (e.g., heritable and socio-demographic characteristics of the mother that predict increased probability of SDP). It also controls for differences between mothers who do and do not smoke during pregnancy, and their partners, that might otherwise artifactually create, or alternatively mask, associations between SDP and child outcomes. Such a design will therefore provide opportunities to determine less biased effect sizes while also allowing us to investigate (on a preliminary basis) the possible contribution of paternal or other second-hand smoke exposure during the pre, peri, and postnatal periods to offspring outcome. This protocol has developed a cohort that can be followed longitudinally through periods typically associated with increased externalizing symptoms and substance used initiation.
\end{abstract}

Keywords: family study, genetics, quasi-experimental design, sibling comparison, smoking during pregnancy

In the United States, maternal SDP continues to be a major public health concern. Rates of SDP vary by individual state, but on average, $12.3 \%$ of women report SDP (Tong et al., 2013). Despite a large literature suggesting undesirable outcomes in children exposed to SDP and warnings encouraging women to stop smoking while pregnant, the decrease in prevalence of SDP during recent years has been non-significant $(13.3 \%$ in 2000 to 12.3\% in 2010; Tong et al., 2013). SDP is associated with multiple adverse birth-related outcomes, such as pre-term delivery (Castles et al., 1999; Shah \& Bracken, 2000), increased risk for spontaneous abortion (Castles et al., 1999), and lower birth weight (e.g., Benjamin-Garner \& Stotts, 2013; Knopik et al., 2015 is in press; KujaHalkola et al., 2014; Marceau et al., 2015 is still under

RECEIVED 9 May 2015; ACCEPTED 26 May 2015. First published online 29 July 2015.

ADDRESS FOR CORRESPONDENCE: Valerie Knopik, Division of Behavioral Genetics, Coro West Suite 204, 1 Hoppin St, Providence, RI 02903, USA. E-mail: valerie_knopik@brown.edu 
review). It has also been associated with prenatal ischemiahypoxia (see Smith et al., 2015 is still under review), respiratory disease (Cook \& Strachan, 1999), cancer later in life (Doherty et al., 2009), and a host of neurodevelopmental and behavioral outcomes (see Knopik, 2009, for a review). Findings also suggest that there are a variety of placental complications linked to prenatal exposure to cigarette smoke (e.g., alterations to the development and function of the placenta; Einarson \& Riordan, 2009), which could effectively translate into a number of sequelae (e.g., intrauterine growth retardation and later behavioral problems; Huizink \& Mulder, 2006; Joya et al., 2014; Knopik, 2009).

Until fairly recently, studies of the effects of SDP did not take into account more precise measurement of parental characteristics or genetic/familial influences that might also contribute to the SDP-outcome relationship. Some early attempts to do this included modeling maternal and paternal psychopathology in twin studies (e.g., Knopik et al., 2005; Maughan et al., 2004; Thapar et al., 2003) and children of twin studies (D'Onofrio et al., 2003; Knopik et al., 2006). The twin design can offer considerable knowledge in the genetic etiology of, not only outcomes of interest (e.g., attention deficit hyperactivity disorder [ADHD]), but also risk factors (e.g., SDP; see Agrawal et al., 2008 for genetic etiology of SDP; D’Onofrio et al., 2003, 2008). It can also determine whether genetic effects differ in two environments; however, twin models may only partially control for how genetic factors may impact outcomes, since they assume that the specified environments represent 'true' or 'pure' environmental risk factors that are free from genetic influences (i.e., that there is no gene-environment correlation; Caspi et al., 2000; D’Onofrio et al., 2003; Purcell \& Koenen, 2005). Further, the prenatal environment is an obligatory shared environment in the twin design (i.e., differential exposure between members of the twin pair is challenging, if not impossible, to determine). Classical twin studies, even those that add explicit measures of the environment, are also not able to delineate the actions involved in intergenerational processes (D'Onofrio et al., 2003). Twin studies that have examined the association of SDP and behavioral outcomes suggest that, once genetic and environmental risks were controlled for, the effects of SDP on conduct disorder were reduced (Maughan et al., 2004); however, despite this reduction for conduct problems, SDP explained a small but significant amount of the variance above and beyond genetic effects on ADHD (e.g., Knopik et al., 2005; Thapar et al., 2003).

The Children-of-Twins (COT) design, which has also been used to investigate SDP-outcome associations, can begin to elucidate the role that specific environments (such as prenatal exposure) play in the etiology of psychological and behavioral phenomena (D'Onofrio et al., 2003), while studying intergenerational associations with fewer assumptions than the twin-family design. In the case of prenatal exposure, it allows one to begin to disentangle genetic, prena- tal exposure, and other environmental effects on offspring outcomes. It also offers the additional advantage of including offspring sibling pairs that may differ in their amounts and/or timing of prenatal exposure (Knopik, 2009). However, there are relatively few COT datasets and even fewer that include detailed assessment of SDP. Results from COT designs addressing the SDP-outcome association yielded a pattern of results consistent with maternal SDP having an independent effect on offspring birth weight (D'Onofrio et al., 2003) and ADHD (Knopik et al., 2006), even after controlling for potential confounders (e.g., genetic transmission, other environmental factors, and other covariates).

The ability to begin to disentangle genetic and environmental intergenerational transmission in the domain of SDP is critical for understanding the magnitude of risk that SDP carries as this can have real implications for future research, intervention, and prevention efforts. It is unlikely that a single design will provide the answers to the complicated nature of the association between SDP and subsequent outcomes, given methodological limitations and the risk factor under consideration (SDP which, in twin offspring, will not differ). Thus, as a general call to the field, Knopik (2009) suggested the importance of a comprehensive approach to studying SDP effects, while also acknowledging the role of genetic influences. D'Onofrio et al. (2013) later called this a 'comprehensive family-based quasi-experimental approach'. The case-crossover design (or within-mother, between-pregnancy design used in the $\mathrm{MO}-\mathrm{MATCH}$ ) is an example of one such approach, which examines siblings discordant for prenatal exposure to SDP. A strength of the case-crossover design is that associations of SDP with a child outcome can be examined both within a family and between families, and results can strengthen our inferences about causality in associations of SDP and child outcomes. The between-family association can be considered consistent with the historically standard comparison of looking at offspring of mothers who smoke during pregnancy relative to offspring of mothers who do not. This comparison does not control for influences that siblings share (i.e., genetic and familial effects) that might confound the SDP-outcome association; however, it does allow replication of historical associations found in the literature. Conversely, the strongest support for a causal influence of SDP on a child outcome (e.g., child ADHD) occurs when there is a within-family association: the exposed sibling has more ADHD symptoms than the unexposed sibling. Because the design controls for mother- and family-level characteristics, and to a certain extent genetic influences, the within-family association is the strongest evidence that SDP may be causally linked with the outcome.

At the time that MO-MATCH was considered for funding and ultimately funded, there were only two studies that considered relatives differentially exposed to prenatal smoking (D’Onofrio et al., 2008; Lambe et al., 2006). These studies drew their samples from larger projects that were not 
necessarily designed to examine SDP, but which had useful data with which to examine these associations. Results suggested that for school performance (Lambe et al., 2006) and conduct problems (D'Onofrio et al., 2008), the observed associations between these outcomes and SDP might not be causal. However, findings for ADHD problems, as measured by the Child Behavior Checklist (CBCL; Achenbach, 1978), were less clear (D’Onofrio et al., 2008). Their comparison of siblings who differed in SDP exposure showed a small but significant effect of SDP on ADHD problems, a finding consistent with Knopik et al. (2006), who used a COT approach.

Over the course of this data collection effort, there has been a surge of interest in the prenatal environment (e.g., D’Onofrio et al., 2010, 2013; Gaysina et al., 2013; Knopik, 2009; Kuja-Halkola et al., 2014; Rice et al., 2009; Thapar et al., 2009; see also upcoming special issue of Behavior Genetics on the prenatal environment). The majority of studies to date have used phenotypes pulled from medical records and national databases. These sources are incredibly useful and offer large sample sizes, but there is a need for purposefully designed deep phenotyping that will allow for more nuanced questions to address the complex nature of the SDP-outcome association. With purposefully designed studies, we can begin to address questions concerning why mothers change their behaviors between pregnancies, a question that, as of yet, has not been available in larger registry-based datasets. More detailed phenotyping allows researchers to approach these questions from angles that are not supported with the larger medical records-based dataset. As one example, incorporating an extensive laboratory-based neuropsychological testing battery offers the potential advantage that laboratory-based measures may be relatively free from bias, whereas checklists, rating scales, and structured interviews can be influenced by a number of factors (Nichols \& Waschbusch, 2004). It also affords the investigation of multiple aspects of the ADHD-related behavior spectrum. For instance, research has suggested that children with ADHD exhibit impairments in executive function and processing speed in realworld activities as well as in neuropsychological testing, and that cognitive deficits detected by standardized neuropsychological testing are related to performance difficulties in real-world activities (e.g., Lawrence et al., 2004). Further, youth exhibit different types of ADHD-related behaviors in the classroom than at home. This observation lends credence to the collection of both parent- and teacher-reported symptoms, each of which are considered valid and provide important insights into how and when children experience ADHD-related impairments (e.g., Lahey et al., 1994).

\section{Overview of the Current Study}

The MO-MATCH study is an ongoing data collection collaboration between Rhode Island Hospital/Brown University and Washington University in St Louis. The Institu- tional Review Boards of Rhode Island Hospital, Washington University, and the State of Missouri Department of Health and Senior Services approved the study. MO-MATCH started as a pilot project in 2004 to determine the feasibility of locating, contacting, and interviewing a specific group of mothers of Missouri-born children. These mothers had, according to birth records (BR), reported smoking during one pregnancy but not during another pregnancy. This withinmother, between-pregnancy design (or sibling comparison design) provides the best possible methodological control for many stable maternal and familial confounding factors (e.g., heritable and socio-demographic characteristics of the mother that predict increased probability of SDP). The design also controls for differences between mothers who do and do not smoke during pregnancy; differences that might otherwise artifactually create, or alternatively mask, an association between SDP and child outcomes. The overarching goals of this project are: (1) to critically investigate prenatal environmental influences on child attention problems and associated learning and cognitive deficits, and (2) to provide a foundation for later characterization of the molecular epidemiology of effects of SDP and offspring attention, learning, and cognition.

\section{Study Hypotheses and Aims}

There were three primary aims for this study. Aim 1 was a procedural aim to enroll and interview a new sample of mothers, identified via BR, and to confirm full sibling pairs discordant for maternal SDP. Following maternal diagnostic telephone interview about each child (assessing pregnancy and life events surrounding pregnancy, early life exposures, and child behavior), these families completed in-depth neuropsychological lab assessment of children and parents (including general cognitive ability, memory, reading, receptive language, executive function). Full sib-ship will be verified via DNA from samples collected from parents and discordant sibling pairs. DNA has currently been isolated and will be stored for future informed molecular analyses. Aim 2 was to assess the effects of SDP on offspring neurocognitive outcomes (especially memory, executive function, lexicon, and reading), capitalizing on the unique withinmother, between-pregnancy comparison. The first hypothesis of Aim 2 was that, when genetic and familial effects are not modeled, SDP will be associated with significant childhood deficits in tests (particularly memory, executive function, receptive language, and reading) that tap brain regions shown in basic science studies to be affected by prenatal nicotine exposure. The second hypothesis of Aim 2 was that sibling comparisons will show attenuated associations, suggesting partial confounding due to influences that siblings share. Aim 3 was to assess the effects of SDP on ADHD, as measured by multiple assessments (see Table 2) and multiple reporters (parent and teacher). We hypothesized that (a) significantly greater ADHD symptoms will 
be found in children who have been exposed to SDP when considering the standard between-mother comparison; and (b) within-mother, between-pregnancy (or sibling comparison) will suggest, at least for maternal reported ADHD variables, partial confounding due to effects that siblings share.

\section{Recruitment Methods}

The literature on SDP heavily guided our decision-making process for recruitment, and the target age range of the offspring in our design was a large deciding factor for our entire recruitment and assessment protocol. Given that ADHD is a clinically significant condition with very clear public health implications, and that neuropsychological alterations, such as executive function, memory, reading, and language, found in school-age populations, are also of public health concern due to the consequences and special services involved, we chose our target offspring age range as $8-15$ years of age. Our justification for this age range is as follows: (1) the uncertainty of findings in infants/toddlers (see Knopik, 2009 for a review) provide a rationale for our focus on an older age group, where apparent deficits are seen more robustly; (2) our research team has considerable experience with assessment administration, clinical treatment, and research with children of the proposed age range; (3) two of our primary outcomes of interest, ADHD and reading, can be adequately studied in this age group (i.e., DSM-IV ADHD criteria suggest that children exhibit behaviors before the age of 7 years, thus they will be through the period of risk for first symptom onset by the time they enter our study; most standard and validated reading assessments are designed for children with a minimum age of 8 years); and (4) the proposed sampling scheme will develop a cohort which, in the future, can be followed longitudinally through periods of increased externalizing symptoms and substance use initiation, abuse, and dependence.

Families were identified using BR obtained from the Missouri Department of Health and Senior Services Bureau of Health Informatics. BR in Missouri, for birth years 19982005 (to target children aged $8-15$ years at the time of testing over the project period), were examined for mothers who changed smoking behavior between two pregnancies. Over 4000 mothers were identified. In order to locate and track these families, our research team had permission to use $\mathrm{BR}$, drivers license records, marriage, and divorce records to assist in locating the best possible contact information for each potential family. These records were supplemented using commercial databases.

Candidate mothers were sent a letter prior to attempts to contact that family by telephone, to introduce them to the study and to tell them that they would be contacted for a brief (10 min) screening interview to determine eligibility. The letter stressed voluntary participation and included a phone number at which families choosing not to partici- pate, or those having concerns or questions, could contact project staff. Attempts were then made to reach the biological mother of the children. Once contacted, the voluntary nature of the study was again explained, and the mother was also told that she could choose not to answer any or all of the questions.

After 1,520 initial screening interviews to verify the primary inclusion criteria obtained through the BR (i.e., mom smoked during one pregnancy but not the other), only $27 \%$ of mothers agreed via screening with the BR (the majority [57\%] reported smoking during both pregnancies, and $16 \%$ reported not smoking for both pregnancies). Once BR information was verified, additional exclusionary criteria were assessed. Families were excluded at this point if: (1) mothers failed to understand the elements of informed consent; (2) English was not the primary language spoken in the home; (3) if the children had a history of head trauma, neurological disorders, or uncorrected visual, or auditory acuity deficits. Additional criteria that precluded participation were: (4) the children did not have the same biological father (as based on maternal report at this point in the protocol); (5) the mother did not have custody of the children; and (6) if one of the children was deceased. Based on evidence (e.g., Morales-Suarez-Varela et al., 2006) suggesting that offspring of non-smokers who used nicotine substitutes (NRT) during pregnancy are at increased risk for congenital malformations, mothers who reported using nicotine substitutes in the 'non-smoking' pregnancy were also excluded.

Once initial eligibility (i.e., mother smoked during one pregnancy but not during another) was confirmed through the screening interview $(N=413)$, brief information about the study was given with opportunity to answer questions, and the mother was invited to complete a diagnostic interview. One hundred and seventeen women declined to participate in the study, after the screening interview, and mothers $(N=70)$ were excluded due to the additional eligibility criteria (criteria 4-6) listed above. If the mother agreed to participate, a respondent booklet containing consent documents and a 10-page packet containing a brochure about future genetic research was mailed to the participant and her family, and an appointment was made for a consent interview (to take place before the diagnostic interview) in which these materials were reviewed with the participants. Once verbal consent was obtained, the maternal telephone diagnostic interviews could take place. At the time that data collection ended for the current project, 173 mothers had consented and completed the entire protocol.

Once the mother was recruited, permission was sought from the mother to contact the birth father. The mother was asked about the birth father's identity (which could confirm BR information, if it was recorded), information about how to locate the birth father, and any potential concerns. Birth fathers were only included if the mother agreed to providing contact information and released his information to the 
TABLE 1

Sample Demographics

\begin{tabular}{|c|c|c|c|c|}
\hline & Mean & $(S D)$ & Min & Max \\
\hline Maternal age & 39.83 & $(5.62)$ & 29 & 54 \\
\hline Paternal age & 44.04 & $(6.34)$ & 33 & 60 \\
\hline Child 1 age & 12.99 & (1.95) & 9 & 16 \\
\hline Child 2 age & 10.19 & $(1.80)$ & 7 & 14 \\
\hline Child age difference & 2.79 & (1.54) & 1 & 7 \\
\hline \# living in home & 4.92 & $(1.40)$ & 3 & 12 \\
\hline Mothers' marital status & $N$ & $\%$ & & \\
\hline Never married & 6 & $4 \%$ & & \\
\hline Married & 130 & $77 \%$ & & \\
\hline Separated & 5 & $3 \%$ & & \\
\hline Divorced & 26 & $15 \%$ & & \\
\hline \multirow[t]{2}{*}{ Widowed } & 2 & $1 \%$ & & \\
\hline & \multicolumn{2}{|c|}{ Maternal } & \multicolumn{2}{|c|}{ Paternal } \\
\hline Education & $N$ & $\%$ & $N$ & $\%$ \\
\hline Less than $\mathrm{HS}$ & 7 & $4 \%$ & 9 & $10 \%$ \\
\hline HS & 30 & $18 \%$ & 19 & $20 \%$ \\
\hline $1-2$ years college & 50 & $30 \%$ & 14 & $15 \%$ \\
\hline $3-4$ years college & 46 & $27 \%$ & 17 & $18 \%$ \\
\hline More than college & 29 & $17 \%$ & 21 & $22 \%$ \\
\hline Not reported & 7 & $4 \%$ & 14 & $15 \%$ \\
\hline Food stamp use & 22 & $11 \%$ & & \\
\hline
\end{tabular}

Note: $N=344$ pregnancies from 173 families. Total $N$ s vary because of randomly missing data.

study. We recruited $54 \%$ of fathers from our 173 families $(N=94)$. Biological paternity will be confirmed via DNA.

In addition to maternal diagnostic interviews in which mothers provide information about their pregnancies and their children's behavior, mothers, fathers (when available), and children traveled to our research offices to complete inperson family laboratory neuropsychological testing. Prior to starting the lab-based session, consent forms for the lab-based session and saliva samples were reviewed and participant understanding was confirmed by project staff. Consent forms (and assent forms for children) were then signed. Mothers also signed a release providing the names of their children's teachers so that project staff could contact teachers to complete questionnaires regarding certain child behaviors. At the completion of the laboratory assessment, the session was concluded and participants were debriefed.

\section{Sample}

Mother-reported data was available on 344 pregnancies and father-reported data was available on 181 pregnancies. Demographic information regarding parent age, child age, education, and marital status are provided in Table 1 . The mean age of mothers and fathers at the time of interview was 39.83 years $(S D=5.62)$ and 44.04 years $(S D=6.34)$, respectively. Parents were primarily of Caucasian ancestry $(96 \%, n=250$; three individuals refused to provide ancestral information). In a comparison to census data for the state of Missouri (census.missouri.edu), the MO-MATCH sample appears consistent with the demographics of the state in terms of marriage rates $(75 \%$ census vs. $77 \% \mathrm{MO}-$ MATCH). MO-MATCH parents show slightly lower rates of stopping at a high school education $(31.6 \%$ census vs.
$18-20 \% \mathrm{MO}-\mathrm{MATCH}$ ) and completing at least 'some graduate school' ( $26.2 \%$ census vs. $17-22 \%$ MO-MATCH), but are consistent with rates of completing 'some college'. The MO-MATCH sample appears to have lower rates of children and families served by food stamps $(20-30 \%$ in the state of Missouri and $11 \%$ in MO-MATCH). MO-MATCH shows higher rates of tobacco usage than state averages, which is expected given the nature of sample selection. Additional sample characteristics are shown in Table 2.

Of the 173 participating families, 94 fathers provided data. We examined possible differences between families where fathers did versus did not participate, using Wilcoxon-Mann-Whitney tests (e.g., non-parametric analog to independent samples $t$ tests) on demographic and study variables. Specifically, we tested for differences where fathers did versus did not participate for: marital status; maternal age; maternal employment status; maternal education; age difference between siblings; the most prevalent maternal diagnoses: nicotine dependence and alcohol abuse; and child 1 and child 2's age, sex, birth weight, SDP severity, and ADHD symptoms (a total of 17 tests). There were only two differences (fewer than expected by chance) in mothers' age and marital status. The remainder of demographic variables and all study variables did not differ for families where fathers did versus did not participate, $\chi^{2}<$ $2.91, p>.05$. Mothers were slightly older in families where fathers participated $(M=41.18, S D=5.36)$ than in families where fathers did not participate $(M=38.17, S D=5.66)$, $\chi^{2}=25.09, p<.05$. Second, families where fathers participated were more likely to have a 'married' status, whereas families with fathers who did not participate had a higher proportion of 'divorced' status, $\chi^{2}=12.89, p<.05$ (families where fathers participated: married $=95.45 \%$, never married $=2.27 \%$, divorced $=2.27 \%$; families where fathers did not participate: married $=54.67 \%$, never married $=$ $6.67 \%$, divorced $=30.67 \%$, separated $=5.33 \%$, widowed $=$ $2.67 \%)$.

\section{Assessment}

This MO-MATCH protocol was carefully chosen to be standard and comprehensive, while also targeting behavioral/cognitive deficits linked to brain regions that have been proposed to be negatively affected by prenatal nicotine exposure. To select phenotypes, we relied on both basic science (i.e., animal) models as well as human studies to identify phenotypes that are suggested to be influenced by maternal SDP. Animal studies (see Knopik, 2009, for a review) have shown a clear effect of prenatal nicotine on offspring behavior. Several studies indicate that chronic prenatal nicotine exposure in rats and mice results in increased receptor density of fetal and neonatal cerebral nicotine acetylcholine receptors (nAChRs; e.g., Slotkin, 1998; Van de Kamp \& Collins, 1994). Up-regulation of the nAChRs during development is conclusive evidence that the cell has experienced 
TABLE 2

Sample Characteristics

\begin{tabular}{|c|c|c|c|c|}
\hline & \multicolumn{2}{|c|}{ Child 1} & \multicolumn{2}{|c|}{ Child 2} \\
\hline & Mean & $(S D)$ & Mean & $(S D)$ \\
\hline \multicolumn{5}{|l|}{ Child Symptoms from diagnostic interview (MAGIC-Parent ${ }^{a}$ ) } \\
\hline Lifetime ADHD inattentive (of 9) & 2.68 & $(3.20)$ & 2.32 & $(3.17)$ \\
\hline Lifetime ADHD hyperactive/impulsive (of 9) & 1.42 & (2.26) & 1.82 & $(2.45)$ \\
\hline Lifetime ADHD total symptoms (of 18) & 4.10 & $(4.87)$ & 4.14 & $(5.11)$ \\
\hline Oppositional defiant (of 8) & 1.52 & (1.66) & 1.42 & $(1.65)$ \\
\hline Conduct disorder (of 15) & 0.38 & $(0.89)$ & 0.32 & $(0.92)$ \\
\hline \multicolumn{5}{|l|}{ ADHD symptoms from normative checklist $\left(S_{W A N}{ }^{a}\right)$} \\
\hline Inattention (of 9) & 2.84 & $(2.74)$ & 3.27 & $(3.06)$ \\
\hline Hyperactive/impulsive (of 9) & 1.52 & $(2.11)$ & 2.63 & $(2.91)$ \\
\hline \multirow[t]{2}{*}{ Total (of 18) } & 4.36 & (4.24) & 5.90 & $(5.50)$ \\
\hline & \multicolumn{2}{|c|}{ Maternal } & \multicolumn{2}{|c|}{ Paternal } \\
\hline Parent psychopathology diagnosis (absence/presence) ${ }^{b}$ & $\mathrm{~N}$ & $\%$ & $\mathrm{~N}$ & $\%$ \\
\hline Nicotine abuse & 16 & $9 \%$ & 14 & $15 \%$ \\
\hline Nicotine dependence & 104 & $62 \%$ & 37 & $39 \%$ \\
\hline Alcohol abuse & 76 & $45 \%$ & 50 & $53 \%$ \\
\hline Alcohol dependence & 20 & $12 \%$ & 17 & $18 \%$ \\
\hline Marijuana abuse & 1 & $<1 \%$ & 0 & \\
\hline Marijuana dependence & 0 & & 0 & \\
\hline Conduct disorder & 1 & $<1 \%$ & 1 & $1 \%$ \\
\hline Present oppositional defiant disorder (ODD) & 2 & $1 \%$ & 0 & \\
\hline Past ODD & 3 & $2 \%$ & 0 & \\
\hline Lifetime ADHD inattentive & 5 & $3 \%$ & 2 & 2 \\
\hline Lifetime ADHD hyperactive/impulsive & 1 & $<1 \%$ & 3 & $3 \%$ \\
\hline Lifetime ADHD combined type & 3 & $2 \%$ & 2 & $2 \%$ \\
\hline Past depressive episode & 68 & $40 \%$ & 1 & $1 \%$ \\
\hline Present depressive episode & 8 & $5 \%$ & 0 & 5 \\
\hline Generalized anxiety & 12 & $7 \%$ & 0 & \\
\hline
\end{tabular}

chronic nicotinic stimulation. The long-term effects of this up-regulation remain unclear (Ernst et al., 2001); although the proposed mode of action suggests that this stimulation results in premature onset of cell differentiation, at the expense of replication, leading to (1) brain cell death, (2) structural changes in regional brain areas, and (3) altered neurotransmitter systems (i.e., norepinephrine, dopamine, and serotonin; Slikker et al., 2005). Such alterations could translate to deficits in later learning, memory, behavior, and development. Differences in developmental profiles of receptor binding between species and strains suggest that genetic factors regulate the maturation of the nicotinic receptor (Van de Kamp \& Collins, 1994). These genetic factors may explain inter-individual differences in sensitivity to the effects of in utero exposure to nicotine (Ernst et al., 2001).

However, the rat, mouse, and other model organism brains are very different from the human brain. Moreover, model organism studies tend to focus only on prenatal nicotine (and can be very controlled in their exposures), whereas in human studies, the fetus is exposed to over 4,000 chemicals in the average cigarette, including a large amount of other toxic components, such as carbon monoxide, ammonia, nitrogen oxide, lead, and other metals (Huizink \& Mulder, 2006). Human studies have been somewhat variable, particularly in studies examining behavioral outcomes (see Knopik, 2009, for a review); however, some of the most robust associations reported tend to be in the externalizing spectrum (i.e., ADHD and conduct disorder). Further, at the time that this project began, there were only a few genetically informed studies considering the role of SDP in child and adolescent behavior, but the ones that were published focused on ADHD and related disruptive behavior. Considered together, animal studies provided a clear biological pathway for possible prenatal nicotine associations with learning and behavior, and human studies tend to converge on an association between SDP and externalizing behaviors (before considering genetic effects). We applied this information to aid in the selection of the primary phenotypes under investigation and the covariates that would be included.

The MO-MATCH assessment includes questionnaires (parent-report and teacher-report), maternal telephone diagnostic interviews, in-person interviews, an extensive neuropsychological testing battery, and collection of DNA. BR data for both children are also available as they are the initial means of finding potential participants. The interviews were semi-structured diagnostic interviews, which allowed project staff to establish rapport with mothers, and computer-assisted personal interviews that were completed privately by mothers and fathers to facilitate confidentiality and honest responses. The incorporation of detailed phenotypic parental assessment (interview and lab-based) increases our ability to identify the potential confounding effects of heritable and socio-demographic characteristics 
TABLE 3

Summary of Core Assessments

\begin{tabular}{|c|c|c|c|}
\hline & Instrument(s) & Method & Rater/Ratee \\
\hline \multicolumn{4}{|l|}{ Parental psychopathology/cognition } \\
\hline $\begin{array}{l}\text { DSM-IV alcohol abuse/dependence, smoking and } \\
\text { tobacco dependence, illicit drug use and } \\
\text { dependence, depression and anxiety disorders, } \\
\text { antisocial behavior, childhood ADHD, childhood } \\
\text { conduct disorder, including family history }\end{array}$ & MAGIC-Adult on Self (Todd et al., 2003) interview & $\mathrm{L}$ & $\mathrm{M} / \mathrm{M}, \mathrm{M} / \mathrm{F}$ \\
\hline General cognitive ability & Wechsler Adult Intelligence Scale (Wechsler, 1997) & $\mathrm{L}$ & $\mathrm{O} / \mathrm{M}, \mathrm{O} / \mathrm{F}$ \\
\hline \multicolumn{4}{|l|}{ Prenatal and perinatal environment } \\
\hline $\begin{array}{l}\text { Pregnancy/birth history (including preterm birth and } \\
\text { birth weight) }\end{array}$ & MAGIC-Parent (Todd et al., 2003) & I & M \\
\hline Prenatal and perinatal exposure to toxins & MAGIC-Parent \& Adult on Self (Todd et al., 2003); & I & $M, F$ \\
\hline \multicolumn{4}{|l|}{$\begin{array}{l}\text { Marital/partner/family relationship and life events } \\
\text { surrounding pregnancy }\end{array}$} \\
\hline $\begin{array}{l}\text { Marital/partner/sib conflict and life events } \\
\text { surrounding pregnancy }\end{array}$ & MAGIC-Parent \& Adult on Self (Todd et al., 2003) & $\mathrm{L}$ & $\mathrm{M} / \mathrm{M}-\mathrm{F}, \mathrm{F} / \mathrm{M}-\mathrm{F}$ \\
\hline \multicolumn{4}{|l|}{ Child behavior/disorder/cognition } \\
\hline General cognitive ability & $\begin{array}{l}\text { Full Scale IQ_-Wechsler Intelligence Scale for Children } \\
\quad \text { (Short Form; Wechsler, 2003; Wechsler et al., 2004) }\end{array}$ & $\mathrm{L}$ & $\mathrm{O} / \mathrm{C}$ \\
\hline \multirow[t]{2}{*}{ Receptive language } & $\begin{array}{l}\text { Peabody Picture Vocabulary Test-III (PPVT-III; Dunn \& } \\
\text { Dunn, 1997) }\end{array}$ & $\mathrm{L}$ & $\mathrm{O} / \mathrm{C}$ \\
\hline & CELF-IV: Word Classes-Receptive (Semel et al., 1995) & L & $\mathrm{O} / \mathrm{C}$ \\
\hline \multirow[t]{5}{*}{ Reading ability } & $\begin{array}{l}\text { Word attack - Woodcock Johnson-III (Woodcock et al., } \\
\text { 2001) }\end{array}$ & $\mathrm{L}$ & $\mathrm{O} / \mathrm{C}, \mathrm{O} / \mathrm{M}, \mathrm{O} / \mathrm{F}$ \\
\hline & $\begin{array}{l}\text { Letter Word Identification - Woodcock Johnson-III } \\
\quad \text { (Woodcock et al., 2001) }\end{array}$ & $\mathrm{L}$ & $\mathrm{O} / \mathrm{C}, \mathrm{O} / \mathrm{M}, \mathrm{O} / \mathrm{F}$ \\
\hline & Spelling - Woodcock Johnson-III (Woodcock et al., 2001) & $\mathrm{L}$ & $\mathrm{O} / \mathrm{C}, \mathrm{O} / \mathrm{M}, \mathrm{O} / \mathrm{F}$ \\
\hline & $\begin{array}{l}\text { GORT-IV - measures reading rate, accuracy, and } \\
\text { comprehension (Wiederholt \& Bryant, 2001) }\end{array}$ & $\mathrm{L}$ & $\mathrm{O} / \mathrm{C}$ \\
\hline & Nelson-Denny Reading Test (Brown et al., 1993) & $\mathrm{L}$ & $\mathrm{O} / \mathrm{M}, \mathrm{O} / \mathrm{F}$ \\
\hline \multirow[t]{3}{*}{ Auditory and visual memory } & $\begin{array}{l}\text { Digits Forward and Spatial Span Forward-Wechsler } \\
\text { Intelligence Scale for Children (Wechsler et al., 2004) or } \\
\text { WAIS in Parents (Wechsler, 1997) }\end{array}$ & $\mathrm{L}$ & $\mathrm{O} / \mathrm{C}, \mathrm{O} / \mathrm{M}, \mathrm{O} / \mathrm{F}$ \\
\hline & $\begin{array}{l}\text { Story Memory and Faces Memory-Children's Memory } \\
\text { Scale (Cohen, 1992) }\end{array}$ & $\mathrm{L}$ & $\mathrm{O} / \mathrm{C}$ \\
\hline & $\begin{array}{l}\text { Logical Memory and Faces Memory-Wechsler Memory } \\
\text { Scale III (Wechsler, 1997) }\end{array}$ & $\mathrm{L}$ & $\mathrm{O} / \mathrm{M}, \mathrm{O} / \mathrm{F}$ \\
\hline \multirow[t]{5}{*}{ Executive function } & Logan Stop Task (Logan, 1994) & $\mathrm{L}$ & $\mathrm{O} / \mathrm{C}$ \\
\hline & $\begin{array}{l}\text { Trail Making Test - Delis Kaplan Executive Function } \\
\text { System (DKEFS; Delis et al., 2001) }\end{array}$ & $\mathrm{L}$ & $\mathrm{O} / \mathrm{C}, \mathrm{O} / \mathrm{M}, \mathrm{O} / \mathrm{F}$ \\
\hline & $\begin{array}{l}\text { Verbal Fluency - Delis Kaplan Executive Function System } \\
\text { (DKEFS; Delis et al., 2001); }\end{array}$ & $\mathrm{L}$ & $\mathrm{O} / \mathrm{C}, \mathrm{O} / \mathrm{M}, \mathrm{O} / \mathrm{F}$ \\
\hline & $\begin{array}{l}\text { Color-Word Interference-Delis Kaplan Executive } \\
\text { Function System (DKEFS; Delis et al., 2001) }\end{array}$ & $\mathrm{L}$ & $\mathrm{O} / \mathrm{C}, \mathrm{O} / \mathrm{M}, \mathrm{O} / \mathrm{M}$ \\
\hline & $\begin{array}{l}\text { Digits Backward \& Spatial Span Backward-Wechsler } \\
\text { Intelligence Scale for Children (Wechsler et al., 2005) or } \\
\text { WAIS and WMS-III in parents (Wechsler, 1997a, 1997b) }\end{array}$ & $\mathrm{L}$ & $\mathrm{O} / \mathrm{C}, \mathrm{O} / \mathrm{M}, \mathrm{O} / \mathrm{F}$ \\
\hline \multirow{4}{*}{ ADHD/externalizing behavior } & MAGIC-Parent (Todd et al., 2003) - maternal report & I & $\mathrm{M} / \mathrm{C}$ \\
\hline & $\begin{array}{l}\text { Child Behavior Checklist 6-18 (CBCL 6-18; Achenbach } \\
\text { 1991a) and Achenbach Teacher Report Form (TRF; } \\
\text { Achenbach, 1991b) }\end{array}$ & $\mathrm{Q}$ & $\mathrm{M} / \mathrm{C}, \mathrm{T} / \mathrm{C}$ \\
\hline & $\begin{array}{l}\text { Conners Rating Scale - Parent and Teacher (Conners } \\
\text { et al., 1998a, 1998b) }\end{array}$ & $\mathrm{Q}$ & $\mathrm{M} / \mathrm{C}, \mathrm{T} / \mathrm{C}$ \\
\hline & $\begin{array}{l}\text { Strengths and Weaknesses of ADHD and Normal } \\
\text { behavior (SWAN, Swanson et al., 2006) }\end{array}$ & $\mathrm{Q}$ & $\mathrm{M} / \mathrm{C}$ \\
\hline Fine motor & Grooved Peg Board (Klove, 1963; Trites, 1977) & $\mathrm{L}$ & $\mathrm{O} / \mathrm{C}$ \\
\hline Substance use/initiation & $\begin{array}{l}\text { Substance Use domain - Youth ver. Drug Use Screening } \\
\text { Inventory-Rev (DUSI-R; Tarter, 1990; Tarter et al., 1994) }\end{array}$ & $L$ & $\mathrm{C} / \mathrm{C}$ \\
\hline \multicolumn{4}{|l|}{ Sociodemographic/contextual } \\
\hline
\end{tabular}

Note: I = Maternal Interview; $\mathrm{Q}=$ Questionnaire; $\mathrm{L}=\mathrm{Lab} ; \mathrm{M}=$ Mother; $\mathrm{F}=$ Father; $\mathrm{C}=$ Child; $\mathrm{O}=$ Observer, $\mathrm{T}=$ Teacher; $\mathrm{MAGIC}=\mathrm{Missouri}$ Assessment for Genetics Interview for Children; GORT-IV = Gray Oral Reading Test — Fourth edition.

that may create false-positive findings in between-family comparisons. Most studies do not control for the fact that prenatal exposures may be correlated with parental behaviors that could also act as important risk factors that are in turn transmitted to their offspring. A listing of the mea- sures administered is presented in Table 3. Reliability information for key measures is presented in Table 4 and supporting the literature identifying the major domains for which SDP effects have been reported is shown in Table 5. 
TABLE 4

Published Reliability Data for Key Constructs in the Assessment Protocol

\begin{tabular}{|c|c|c|c|c|}
\hline Child development/disorder & Measure & $\begin{array}{l}\text { Coefficient alpha } \\
\text { (internal consistency) }\end{array}$ & $\begin{array}{l}\text { Short-term } \\
\text { test-retest }\end{array}$ & $\begin{array}{l}\text { Interrater } \\
\text { reliability }\end{array}$ \\
\hline General cognitive ability & WISC-IV-INT Full Scale IQ & 0.97 & 0.93 & \\
\hline \multirow[t]{2}{*}{ Receptive language } & PPVT-III & $0.92-0.98$ & 0.90 & \\
\hline & CELF-4 Word Classes-Receptive & 0.82 & $0.83-0.91$ & \\
\hline \multirow[t]{3}{*}{ Auditory and visual memory } & $\begin{array}{l}\text { WISC-IV-INT: Digit Span Forward and } \\
\text { Spatial Span Forward }\end{array}$ & 0.87 & 0.83 & \\
\hline & CMS Stories & 0.80 & & \\
\hline & CMS Faces & 0.80 & & \\
\hline \multirow{5}{*}{ Executive functioning } & DKEFS Trail Making & $0.57-0.79$ & & \\
\hline & DKEFS Verbal Fluency & $0.68-0.81$ & & \\
\hline & DKEFS Color-Word Interference & $0.62-0.70$ & & \\
\hline & Logon Stop Task & 0.90 & & \\
\hline & $\begin{array}{l}\text { WISC-IV-INT: Digit Span Backward } \\
\text { and Spatial Span Backward. }\end{array}$ & 0.87 & 0.83 & \\
\hline Fine motor & Grooved Peg Board & & 0.86 & \\
\hline \multirow[t]{5}{*}{ Reading } & WJ-III Letter Word Identification & 0.94 & & \\
\hline & WJ-III Word Attack & 0.87 & & \\
\hline & WJ-III Spelling & 0.95 & & \\
\hline & GORT-4 & $0.91-0.97$ & $0.78-0.95$ & \\
\hline & Nelson Denny & $0.88-0.95$ & & \\
\hline \multirow[t]{9}{*}{ ADHD/Externalizing behavior } & MAGIC ADHD present & & & 0.97 \\
\hline & MAGIC ADHD past & & & 0.96 \\
\hline & $\begin{array}{l}\text { MAGIC endorsement of } 18 \text { Criterion } \\
\text { A symptoms }\end{array}$ & & & 0.97 \\
\hline & Conners Parent & $0.83-0.91$ & & \\
\hline & Conners Teachers & $0.88-0.94$ & & \\
\hline & $\begin{array}{l}\mathrm{CBCL} \text { combined for males and } \\
\text { females }\end{array}$ & 0.84 & 0.89 & \\
\hline & $\begin{array}{l}C B C L \text { for mother-father report on } \\
\text { females }\end{array}$ & & & $0.65-0.69$ \\
\hline & $\begin{array}{l}\mathrm{CBCL} \text { for mother-father report on } \\
\text { males }\end{array}$ & & & $0.72-0.75$ \\
\hline & CBCL TRF & $0.72-0.95$ & & \\
\hline
\end{tabular}

Note: WISC-IV-INT: Wechsler Intelligence Scale for Children (Short Form); PPVT-III: Peabody Picture Vocabulary Test-III; CELF-4: Clinical Evaluation of Language CMS: Children's Memory Scale; DKEFS: Delis Kaplan Executive Function System; Logan: Logan Stop Task; Fundamentals - Fourth Edition; WJ-III: Woodcock Johnson-III; GORT: Gray Oral Reading Test — Fourth edition; CBCL: Child Behavior Checklist; TRF: Teacher's Report Form.

Of primary importance to the study aims, both the semistructured telephone diagnostic interview (Missouri Assessment of Genetics Interview for Children-Parent on Child [MAGIC-Parent on Child]; Todd et al., 2003) and the personal computerized interviews completed by mothers and fathers (MAGIC-Adult on Self; Todd et al., 2003) assess detailed assessment of SDP. The MAGIC-Adult on Self also includes questions regarding tobacco exposure during and after pregnancy, and assesses tobacco use by mother, father, or significant other, and any other person living in the household such as a relative or older sibling, during and after pregnancy into the first five years of the child's life. The questions ask about specific time periods, including overall pregnancy, first, second, and third trimester, first six months of child's life, second six months of child's life, and second through fifth years of life. The total number of smokers in the home during these periods is also assessed.

The protocol includes maternal and teacher report of child externalizing behavior (e.g., ADHD), lab-based assessment of major domains of child cognition, lexicon, memory, executive function, fine motor, and reading, complementary lab-based assessment of these domains in parents, as well as assessment of parental psychopathology.
The protocol also includes assessment of environmental risks through which parental psychopathology and related prenatal, and possibly perinatal, substance use are hypothesized to impact child outcome, within-family risks (prenatal substance use, prenatal care); and between-family environmental risks (socio-demographic disadvantage). While this protocol has been carefully selected to be comprehensive, we focus this project on four key domains where we expect, based on basic animal work and existing human work, to find true deficits: memory, executive function, reading/lexicon, and ADHD (see Table 5 for domains and supporting the literature).

\section{Retrospective Report of SDP}

The first paper using MO-MATCH data (Knopik et al., under review) examined rates of agreement across BR report of SDP, retrospective maternal report of SDP, and retrospective paternal report of SDP. Specifically, we compared reports for any SDP during pregnancy and for quantity of cigarettes smoked across each pregnancy. We then compared rates of agreement for changes in SDP behavior from one pregnancy to another. This is a key first step, as 
TABLE 5

Measure-Linked Domains, Component Key Constructs, and Empirical Basis for Testing

\begin{tabular}{|c|c|c|}
\hline Key child outcomes & Child outcome measured by: & Empirical basis for testing \\
\hline \multirow[t]{3}{*}{ Auditory memory } & 1. Digit Span Forward (WISC) & $\begin{array}{l}\text { Fried, O'Connell et al. (1992), Fried, } \\
\text { Watkinson et al. (1992) }\end{array}$ \\
\hline & 2. Story Memory (CMS) & McCartney et al. (1994) \\
\hline & & Roy et al. (2002) \\
\hline \multirow[t]{2}{*}{ Visual memory } & 1. Faces Memory (CMS) & Cornelius et al. (2001) \\
\hline & 2. Spatial Span Forward (WISC) & Roy et al. (2002) \\
\hline \multirow[t]{7}{*}{ Executive function (EF) } & 1. Cognitive Flexibility (DKEFS) & Willcutt et al. (2000) \\
\hline & 2. Verbal Fluency (DKEFS) & Arnsten (1998) \\
\hline & 3. Interference Control (DKEFS) & Cabeza \& Nyberg (1997) \\
\hline & 4. Response Inhibition (Logan) & $\begin{array}{l}\text { Fried, O'Connell et al. (1992), Fried, } \\
\text { Watkinson et al. (1992) }\end{array}$ \\
\hline & 5. Working memory: Digit Span Backward (WISC) & $\begin{array}{l}\text { Fried, O'Connell et al. (1992), Fried, } \\
\text { Watkinson et al. (1992) }\end{array}$ \\
\hline & 6. Working memory: Spatial Span Backward (WISC) & McCartney et al. (1994) \\
\hline & & Roy et al. (2002) \\
\hline \multirow{8}{*}{$\begin{array}{l}\text { Reading and receptive } \\
\text { language }\end{array}$} & 1. Receptive Vocabulary (PPVT-III) & Makin et al. (1991) \\
\hline & 2. Receptive Language (CELF-4) & $\begin{array}{l}\text { Fried, O'Connell et al. (1992), Fried, } \\
\text { Watkinson et al. (1992) }\end{array}$ \\
\hline & & Bauman et al. (1991) \\
\hline & & McCartney et al. (1994) \\
\hline & 3. Single-Word Reading (WJ-III) & Bauman et al. (1991) \\
\hline & 4. Nonword Reading (WJ-III) & McCartney et al. (1994) \\
\hline & 5. Reading Comprehension (GORT) & Fried et al. (1997) \\
\hline & 6. Reading Fluency (GORT) & \\
\hline \multirow[t]{3}{*}{$\begin{array}{l}\text { Attention deficit hyperactive } \\
\text { disorder (ADHD) }\end{array}$} & 1. DSM-IV symptom count or diagnosis & $\begin{array}{l}\text { Fried, O'Connell et al. (1992), Fried, } \\
\text { Watkinson et al. (1992) }\end{array}$ \\
\hline & 2. Conners' Rating Form & D'Onofrio et al. (2008) \\
\hline & $\begin{array}{l}\text { 3. Achenbach series: } \mathrm{CBCL} / \mathrm{TRF} \\
\text { 4. SWAN }\end{array}$ & \\
\hline
\end{tabular}

Note: WISC: Wechsler Intelligence Scale for Children (Short Form); CMS: Children's Memory Scale; DKEFS: Delis Kaplan Executive Function System; Logan: Logan Stop Task; PPVT-III: Peabody Picture Vocabulary Test-III; CELF-4: Clinical Evaluation of Language Fundamentals - Fourth edition; WJ-III: Woodcock Johnson-III; GORT: Gray Oral Reading Test — Fourth edition; CBCL: Child Behavior Checklist; TRF: Teacher's Report Form; SWAN: Strengths and Weaknesses of Attention-Deficit/Hyperactivity Disorder and Normal Behavior Scale.

results will inform every subsequent model fitted to these data. Once predictive utility of various reports of SDP was determined, we then fit a sibling comparison model to examine the association between SDP and birth weight. This approach controls for genetic and familial influences that make the siblings similar and provides a test of whether SDP has an independent effect on birth weight once effects that siblings share are taken into account. Results showed high agreement between reporters and support the utility of retrospective report of SDP. Further, we replicated a causal association between SDP and birth weight, wherein SDP results in reduced birth weight even when accounting for genetic and familial confounding factors via a sibling comparison approach.

\section{Plans for Future Research}

Composite indices for each domain (see Table 4) will be constructed in order to pursue hypothesis testing. Further, in instances where we have multiple reporters, we will create composites consistent with the gold-standard in the clinical literature. When the associations between measures (for the same construct) are low-to-moderate, we will forego composites and analyze measures separately. The rich data collection allows for many avenues of further research. For example, in addition to the primary aims of this project, we will explore reasons why these sibling pairs differ in their exposure to SDP. More specifically, we investigate why these mothers changed their smoking behaviors from one pregnancy to another. Our assessment protocol included questions related to stressors and complications surrounding pregnancy that will aid our efforts in this domain. Another additional area of research will allow us to begin to explore the effects of maternal passive exposure to environmental tobacco exposure (ETS) during pregnancy, child's postnatal exposure to ETS, and possible contributions of paternal or household smoking in the pre, peri, and postnatal periods to offspring outcome.

\section{Conclusion}

The MO-MATCH study, while still in the early stages of data analysis, has the potential to be an important and distinctive asset to the field of prenatal exposure. Not only is this study among the first specifically designed US-based family studies (i.e., not a convenience sample pulled from a larger study designed for other purposes) to leverage the sibling comparison approach to prenatal smoke exposure, but it is also positioned to begin to characterize the molecular epidemiology of effects of SDP, both genetic and epigenetic, on 
carefully selected phenotypes such as offspring attention, learning, and cognition. Further, not only can this study begin to disentangle SDP effects from genetic/familial effects, it can also begin to achieve an accurate assessment of the magnitude of the association between SDP, ADHD, and neuropsychological outcomes. This more refined effect size is of great public health significance because this information could help clarify what are and are not potential causes of ADHD and other neuropsychological deficits seen in school-aged children, findings that can inform treatment providers and prevention efforts concerning how to treat the public health concern of SDP. The future of the MOMATCH study may include tracking the sample into high school and early adulthood, with assessments of additional behavior problems and substance use as well as additional assessments of neighborhood constructs. As an invaluable complement to larger samples with less detailed phenotypic assessment, we are confident that the MO-MATCH data will provide a valuable scientific resource in the years ahead.

\section{Acknowledgments}

This work was supported by NIH grants: DA023134 (Knopik), DA17671 (Knopik), AA07728 AA07728 (Heath), AA09022 (Heath), AA11998 (Heath), HD049024 (Heath), AA017688 (Heath), AA021492 (Heath). Dr. Marceau is supported by T32 DA016184. Dr Palmer is supported by K01 AA021113 and L30 TR001045.

\section{References}

Achenbach, T. M. (1978). The child behavior profile: I. Boys aged 6-11. Journal of Consulting and Clinical Psychology, 46, 478-488.

Achenbach, T. M. (1991a). Manual for the Child Behavior Checklist/4-18 and 1991 profile. Burlington, VT: University of Vermont, Department of Psychiatry.

Achenbach, T. M. (1991b). Manual of the Teacher's Report Form and 1991 profile. Burlington, VT: University of Vermont, Department of Psychiatry.

Agrawal, A., Knopik, V. S., Pergadia, M. L., Waldron, M., Bucholz, K. K., Heath, A. C., . . Martin, N. G. (2008). Correlates of cigarette smoking during pregnancy and its genetic and environmental overlap with nicotine dependence. Nicotine and Tobacco Research, 10, 567-578.

Arnsten, A. F. T. (1998). Catecholamine modulation of prefrontal cortical cognitive function. Trends in Cognitive Sciences, 2, 436-447.

Bauman, K. E., Flewelling, R. L., \& LaPrelle, J. (1991). Parental cigarette smoking and cognitive performance of children. Health Psychology, 8, 97-105.

Benjamin-Garner, R., \& Stotts, A. (2013). Impact of smoking exposure change on infant birthweight among a cohort of women in a prenatal smoking cessation study. Nicotine \& Tobacco Research, 15, 685-692.
Brown, J. I., Fishco, V. V., \& Hanna, G. (1993). The Nelson Denny Reading Test. Chicago, IL: The Riverside Publishing Company.

Cabeza, R., \& Nyberg, L. (1997). Neural bases of learning and memory: Functional neuroimaging evidence. Current Opinions in Neurology, 13, 415-421.

Caspi, A., Taylor, A., Moffitt, T. E., \& Plomin, R. (2000). Neighborhood deprivation affects children's mental health: Environmental risks identified in a genetic design. Psychological Science, 11, 338-342.

Castles, A., Adams, E. K., Melvin, C. L., Kelsch, C., \& Boulton, M. L. (1999). Effects of smoking during pregnancy. Five meta-analyses. American Journal of Preventative Medicine, 16, 208-215.

Cohen, M. J. (1992). Children's Memory Scale. San Antonio, TX: The Psychological Corporation.

Conners, C. K., Sitarenios, G., Parker, J. D., \& Epstein, J. N. (1998a). The revised Conners' Parent Rating Scale (CPRS$\mathrm{R})$ : Factor structure, reliability, and criterion validity. Journal of Abnormal Child Psychology, 26, 257-268.

Conners, C. K., Sitarenios, G., Parker, J. D., \& Epstein, J. N. (1998b). Revision and restandardization of the Conners Teacher Rating Scale (CTRS-R): Factor structure, reliability, and criterion validity. Journal of Abnormal Child Psychology, 26, 279-291.

Cook, D. G., \& Strachan, D. P. (1999). Health effects of passive smoking-10: Summary of effects of parental smoking on the respiratory health of children and implications for research. Thorax, 54, 357-366.

Cornelius, M. D., Ryan, C. M., Day, N. L., Goldschmidt, L., \& Willford, J. A. (2001). Prenatal tobacco effects on neuropsychological outcomes among preadolescents. Journal of Developmental and Behavioral Pediatrics, 22, 217-225.

Delis, D, Kaplan, E., Kramer, J. (2001). Delis-Kaplan executive function system (D-KEFS). Psychological Corporation: A Harcourt Assessment Company.

Doherty, S. P., Grabowski, J., Hoffman, C., Ng, S. P., \& Zelikoff, J. T. (2009). Early life insult from cigarette smoke may be predictive of chronic diseases later in life. Biomarkers, 14, 97-101.

D’Onofrio, B. M., Lahey, B. B., Turkheimer, E., \& Lichtenstein, P. (2013). The critical need for family based, quasiexperimental research in integrating genetic and social science research. American Journal of Public Health, 103, S46S55.

D’Onofrio, B. M., Singh, A. L., Iliadou, A., Lambe, M., Hultman, C. M., Grann, M., ... Lichtenstein, P. (2010). Familial confounding of the association between maternal smoking during pregnancy and offspring criminality: A population-based study in Sweden. Archives of General Psychiatry, 67, 529-538.

D’Onofrio, B. M., Turkheimer, E. N., Eaves, L. J., Corey, L. A., Berg, K., Solaas, M. H., \& Emery, R. E. (2003). The role of the children of twins design in elucidating causal relations between parent characteristics and child outcomes. Journal of Child Psychology and Psychiatry, 44, 11301144. 
D’Onofrio, B. M., Van Hulle, C. A., Waldman, I. D., Rodgers, J. L., Harden, K. P., Rathouz, P. J., \& Lahey, B. B. (2008). Smoking during pregnancy and offspring externalizing problems: An exploration of genetic and environmental confounds. Development and Psychopathology, 20, 139-164.

Dunn, L., \& Dunn, L. (1997). Peabody Picture Vocabulary Test - Third Edition (PPVT-III). Circle Pines, MN: American Guidance Service.

Einarson, A., \& Riordan, S. (2009). Smoking in pregnancy and lactation: A review of risks and cessation strategies. European Journal of Clinical Pharmacology, 65, 325-330.

Ernst, M., Moolchan, E. T., \& Robinson, M. L. (2001). Behavioral and neural consequences of prenatal exposure to nicotine. Journal of the American Academy of Child \& Adolescent Psychiatry, 40, 630-641.

Fried, P. A., O’Connell, C. M., \& Watkinson, B. (1992). 60and 72-month follow-up of children prenatally exposed to marijuana, cigarette, and alcohol: Cognitive and language assessment. Journal of Developmental \& Behavioral Pediatrics, 13, 383-391.

Fried, P. A., Watkinson, B., \& Gray, R. (1992). A follow-up study of attentional behavior in 6-year old children exposed prenatally to marijuana, cigarettes, and alcohol. Neurotoxicity and Teratology, 14, 299-311.

Fried, P. A., Watkinson, B., \& Siegal, L. S. (1997). Reading and language in 9- to 12-year-olds prenatally exposed to cigarettes and marijuana. Neurotoxicology and Teratology, 19, 171-183.

Gaysina, D., Fergusson, D. M., Leve, L. D., Horwood, J., Reiss, D., Shaw, D. S., ... Harold, G. T. (2013). Maternal smoking during pregnancy and offspring conduct problems: evidence from 3 independent genetically sensitive research designs. JAMA Psychiatry. 70, 956-963.

Hollingshead, A. A. (1975). Four-factor index of social status. Unpublished manuscript, Yale University, New Haven, CT.

Huizink, A. C., \& Mulder, E. J. H. (2006). Maternal smoking, drinking, or cannabis use during pregnancy and neurobehavioral and cognitive functioning in human offspring. Neuroscience and Behavioral Reviews, 30, 24-41.

Joya, X., Manzano, C., Álvarez, A. T., Mercadal, M., Torres, F., Salat-Batlle, J., \& Garcia-Algar, O. (2014). Transgenerational exposure to environmental tobacco smoke. International Journal of Environmental Research and Public Health, $11,7261-7274$.

Klove, H. (1963). Clinical neuropsychology. In F. M. Foster (Ed.), The medical clinics of North America. Vol. 47, (pp. 1647-1658). New York: Saunders.

Knopik, V.S. (2009). Maternal smoking during pregnancy and child outcomes: Real or spurious effect? Developmental Neuropsychology, 34, 1-36.

Knopik, V. S., Heath, A. C., Jacob, T., Slutske, W. S., Bucholz, K. K., Madden, P. A. F., ... Martin, N. G. (2006). Maternal alcohol use disorder and offspring ADHD: Disentangling genetic and environmental effects using a children-of-twins design. Psychological Medicine, 36, 1461-1472.

Knopik, V. S., Marceau, K., Palmer, R. H. C., Smith, T. F., \& Heath, A. C. (in press). Maternal smoking during preg- nancy and offspring birth weight: A genetically-informed approach incorporating multiple raters. Behavior Genetics.

Knopik, V. S., Sparrow, E. P., Madden, P. A. F., Bucholz, K. K., Hudziak, J. J., Reich, W., ... Heath, A. C. (2005). Contributions of parental alcoholism, prenatal substance exposure, and genetic transmission to child ADHD risk: A female twin study. Psychological Medicine, 35, 625-635.

Kuja-Halkola, R., D’Onofrio, B. M., Larsson, H., \& Lichtenstein, P. (2014). Maternal smoking during pregnancy and adverse outcomes in offspring: Genetic and environmental sources of covariance. Behavior Genetics, 44, 456-467.

Lahey, B. B., Applegate, B., McBurnett, K., Biederman, J., Greenhill, L., Hynd, G. W., \& Richters, J. (1994). DSMIV field trials for attention deficit hyperactivity disorder in children and adolescents. American Journal of Psychiatry, 151, 1673-1685.

Lambe, M., Hultman, C., Torrang, A., MacCabe, J., \& Cnattingius, S. (2006). Maternal smoking during pregnancy and school performance at age 15. Epidemiology, 17, 524530 .

Lawrence, V., Houghton, S., Douglas, G., Durkin, K., Whiting, K., \& Tannock, R. (2004). Executive function and ADHD: A comparison of children's performance during neuropsychological testing and real-world activities. Journal of Attention Disorders, 7, 137-149.

Logan, G. D. (1994). On the ability to inhibit thought and action: A users' guide to the stop signal paradigm. In D. Dagenbach \& H. Carr (Eds.), Inhibitory processes in attention, memory, and language (pp. 189-239). San Diego, CA: Academic Press.

Makin, J, Fried, P. A., \& Watkinson, B. (1991). A comparison of active and passive smoking during pregnancy: Long term effects. Neurotoxicology and Teratology, 13, 5-12.

Marceau, K., Palmer, R. H. C., Neiderhiser, J. M., Smith, T. F., \& Knopik, V. S. (2015). Passive rGE or developmental geneenvironment cascade? An investigation of the role of xenobiotic genes in the association between smoking during pregnancy and child birthweight. Manuscript submitted for publication.

Maughan, B., Taylor, A., Caspi, A., \& Moffitt, T. E. (2004). Prenatal smoking and early childhood conduct problems. Archives of General Psychiatry, 61, 836-843.

McCartney, J. S., Fried, P. A., \& Watkinson, B. (1994). Central auditory processing in school-age children prenatally exposed to cigarette smoke. Neurotoxicology and Teratology, 16, 269-276.

Morales-Suarez-Varela, M. M., Bille, C., Christensen, K., \& Olson, J. (2006). Smoking habits, nicotine use, and congenital malformations. Obstetrics and Gynecology, 107, 51-57.

Nichols, S. L., \& Waschbusch, D. A. (2004). A review of the validity of laboratory cognitive tasks used to assess symptoms of ADHD. Child Psychiatry and Human Development, 34, 297-315.

Purcell, S., \& Koenen, K.C. (2005). Environmental mediation and the twin design. Behavior Genetics, 35, 491-498.

Rice, F., Harold, G. T., Bolvin, J., Hay, D. F., Van den Bree, M., \& Thapar, A. (2009). Disentangling prenatal and inherited 
influences in humans with an experimental design. PNAS, 106, 2464-2467.

Roy, T. S., Seidler, F. J., \& Slotkin, T. A. (2002). Prenatal nicotine exposure evokes alterations of cell structure in hippocampus and somatosensory cortex. Journal of Pharmacology and Experimental Therapeutics, 300, 124-133.

Semel, E., Wiig, E. H., \& Secord, W. A. (1995). Clinical evaluation of language fundamentals: Third edition examiner's manual. San Antonio, TX: The Psychological Corporation.

Shah, N. R., \& Bracken, M. B. (2000). A systematic review and meta-analysis of prospective studies on the association between maternal cigarette smoking and preterm delivery. American Journal of Obstetrics \& Gynecology, 182, 465-472.

Slikker, W. Jr., Xu, Z. A., Levin, E. D., \& Slotkin, T. A. (2005). Mode of action: Disruption of brain cell replication, second messenger, and neurotransmitter systems during development leading to cognitive dysfunction - developmental toxicity of nicotine. Critical Reviews of Toxicology, 35, 703711.

Slotkin, T. A. (1998). Fetal nicotine or cocaine exposure: Which one is worse? Journal of Pharmacology and Experimental Therapeutics, 285, 931-945.

Smith, T. F., Schmidt-Kastner, R., McGeary, J. E., Kaczorowski, J. A., \& Knopik, V.S. (2015). Prenatal ischemia-hypoxia, the ischemia-hypoxia response pathway, and ADHD risk. Manuscript submitted for publication.

Swanson, J. M., Schuck, S., Mann, M., Carlson, C., Hartman, K., Sergeant, J. A., ... McCleary, R. (2006). Categorical and dimensional definitions and evaluations of symptoms of ADHD: The SNAP and SWAN rating scales. Retrieved from http://www.ADHD.net.

Tarter, R. E. (1990) Evaluation and treatment of adolescent substance abuse: A decision tree method. American Journal of Drug and Alcohol Abuse, 16, 1-46.

Tarter, R. E., Mezzich, A. C., Kirisci, L., \& Kaczynski, N. A. (1994). Reliability of the drug use screening inventory among adolescent alcoholics. Journal of Child \& Adolescent Substance Abuse, 3, 25-36.

Thapar, A., Fowler, T., Rice, F., Scourfield, J., van den Bree, M., Thomas, H., \& Hay, D. (2003). Maternal smoking during pregnancy and attention deficit hyperactivity disorder symptoms in offspring. American Journal of Psychiatry, 160, 1985-1989.

Thapar, A., Rice, F., Hay, D., Boivin, J., Langley, K., van den Bree, M., .. \& \& Harold, G. (2009). Prenatal smoking might not cause attention-deficit/hyperactivity disorder: Evidence from a novel design. Biological Psychiatry, 66, 722-727.

Todd, R. D., Joyner, C. A., Heath, A. C., Neuman, R. J., \& Reich, W. (2003). Reliability and stability of a semi-structured DSM-IV interview designed for family studies. Journal of the American Academy of Child and Adolescent Psychiatry, $42,1460-1468$.

Tong, V. T., Dietz, P. M., Morrow, B., D’Angelo, D. V., Farr, S. L., Rockhill, K. M., \& England, L. J. (2013). Trends in smoking before, during, and after pregnancy - pregnancy risk assessment monitoring system, United States, 40 sites, 2000-2010. Morbidity and Mortality Weekly Report, 62(SS06), 1-19.

Trites, R. L. (1977). Neuropsychological Test Manual. Ottawa, Canada: Royal Ottawa Hospital.

Van de Kamp, J. L., \& Collins, A. C. (1994). Prenatal nicotine alters nicotinic receptor development in the mouse brain. Pharmacology Biochemistry \& Behavior, 47, 889-900.

Wechsler, D. (1997a). Wechsler adult intelligence scale (3rd ed.), San Antonio, TX: The Psychological Corporation.

Wechsler, D. (1997b). Wechsler Memory Scale (3rd ed.), San Antonio, TX: The Psychological Corporation.

Wechsler, D. (2003). Wechsler intelligence scale for children (4th ed.), San Antonio, TX: The Psychological Corporation.

Wechsler, D., Kaplan, E., Fein, D., Kramer, J., Morris, R., Delis, D., ... Maerlender, A. (2004). Wechsler intelligence scale for children (4th ed.), Integrated. San Antonio, TX: Harcourt Assessment.

Wiederholt, J. L., \& Bryant, B. R. (2001). Gray oral reading tests (4th ed.), Examiner's manual. Austin TX: PRO-ED.

Willcutt, E. G., Pennington, B. G., \& DeFries, J. C. (2000). Twin study of the etiology of comorbidity between reading disability and attention-deficit/hyperactivity disorder. American Journal of Medical Genetics, 96, 293-301.

Woodcock, R. W., McGrew, K. S., \& Mather, N. (2001). Woodcock Johnson (3rd ed.), (WJ III). Rolling Meadows, IL: Riverside Publishing Company. 